\title{
Defining the Neural Kinome: Strategies and Opportunities for Small Molecule Drug Discovery to Target Neurodegenerative Diseases
}

Andrea I. Krahn, Carrow Wells, David H. Drewry, Lenore K. Beitel, Thomas M. Durcan, Alison D. Axtman*

\begin{abstract}
:
Kinases are highly tractable drug targets that have reached unparalleled success in fields such as cancer but whose potential has not yet been realized in neuroscience. There are currently 55 approved small molecule kinase-targeting drugs, 48 of which have an anti-cancer indication. The intrinsic complexity linked to central nervous system (CNS) drug development and a lack of validated targets has hindered progress in developing kinase inhibitors for CNS disorders when compared to other therapeutic areas such as oncology. Identification and/or characterization of new kinases as potential drug targets for neurodegenerative diseases will create opportunities for development of CNS drugs in the future. The track record of kinase inhibitors in other disease indications supports the idea that with the best targets identified small molecule kinase modulators will become impactful therapeutics for neurodegenerative diseases.
\end{abstract}

\section{KEYWORDS:}

kinase, neurodegeneration, CNS, Alzheimer's disease, Parkinson's disease, amyotrophic lateral sclerosis, KCGS, GWAS, SNP, IDG, SGC, iPSCS

\section{KEY CONCEPTS:}

Chemical probe: a high-quality small molecule that is potent, selective, and cell-active that meets the following criteria: (1) in vitro biochemical I $C_{50}<50 \mathrm{nM},(2) \geq 30$-fold selectivity relative to other kinases in a large assay panel such as DiscoverX scanMAX, and (3) cellular activity or target engagement with an $\mathrm{IC}_{50}$ $<1 \mu \mathrm{M}$

Narrow spectrum: a selectivity threshold that can be defined as potently inhibiting $\sim 10 \%$ or less of all kinases screened

Kinome: all human kinases

Kinase chemogenomic set (KCGS): publicly-available curated physical library of narrow spectrum and potent kinase inhibitors for which the SGC-UNC has received permission to share the compounds; subsequent releases will increase kinome-wide coverage

Illuminating the Druggable Genome (IDG) program: several interconnected projects currently funded by the National Institutes of Health to provide information on historically understudied members within protein families that have provided drug targets; the three main focus areas are kinases, G-protein coupled receptors, and ion channels

IDG kinase: a kinase that was nominated as dark (understudied) by the National Institutes of Health IDG program (curated list found here: https://druggablegenome.net/IDGProteinList); IDG consortium members generate data and resources to aid in the illumination of the function of these kinases

DK tool: a narrow spectrum inhibitor that exhibits a defined selectivity score $\left(S_{10}(1 \mu M)<0.05\right)$ and cellular target engagement with an $\mathrm{IC}_{50}<1 \mu \mathrm{M} ; \mathrm{S}_{10}(1 \mu \mathrm{M})$ is a measure of selectivity equal to the percentage of screened kinases biochemically inhibited by $>90 \%$ at $1 \mu \mathrm{M}$

\section{INTRODUCTION}

There is an urgent and growing need for new drugs to treat chronic neurogenerative diseases, as life expectancies continue to increase and, correspondingly, the number of patients rises on an annual basis. Unfortunately, there is still much to be learned about the pathogenesis of these complex brain disorders and the ability to treat them is often hampered by the difficulties associated with diagnosis, leading to intervention too late. The heterogeneity of these diseases contributes to their complexity. 
Neurodegenerative disorders are often diverse syndromes with multiple subtypes and the one-size-fitsall treatment model, therefore, results in failure. Following the approach that has yielded clinical success in oncology, personalized medicine could similarly be applied to neurodegeneration. This situation is further complicated by the fact that the likelihood of U.S. Food and Drug Administration (FDA) approval for CNS drugs is approximately half that for drugs with a peripheral target and the approval process takes nearly twice as long as for an oncology drug. ${ }^{1,2}$ Finally, the failure of many advanced clinical trials in the area of Alzheimer's disease (AD) and other diseases of the brain has caused many pharmaceutical companies to exit the neuroscience research and development space, reducing the resources being invested to address the problem.

As an impetus to drive CNS-based kinase drug discovery, we provide insight into the tractability of a subset of human kinases with links to neurodegeneration in this review. Rather than focusing on the few widely studied kinases around which most of the data, reagents, and small molecules have been generated, we instead concentrate on detailing the chemical tools and biology that will encourage and enable the study of lesser studied (also known as understudied or dark) kinases. This focus on the understudied kinome is aligned with that of the Structural Genomics Consortium (SGC), which aims to promote the exploration of currently understudied, but potentially disease-relevant proteins across the human proteome. ${ }^{3}$ In addition to characterizing which kinases fall into this understudied subcategory, we offer high-quality chemical starting points that can be used to modulate their activity. Furthermore, through data mining, we have tabulated genetic links between understudied kinases and the most common adult-onset neurogenerative diseases: $A D$, Parkinson's disease (PD), and amyotrophic lateral sclerosis (ALS).

Since not all protein kinase targets can be covered in a single review, we provide an overview of promising understudied human protein kinase targets for AD, PD, and ALS. Furthermore, we focus our attention on tractable kinases for which there exists a small molecule with narrow selectivity profile against the screenable human kinome (i.e. a non-promiscuous kinase inhibitor). The Illuminating the Druggable Genome (IDG) program has identified many of these understudied kinases on their understudied protein list (https://druggablegenome.net/IDGProteinList). We conclude with a discussion of the challenges that remain with respect to small molecule development for validated biological targets in neurodegenerative disorders.

\section{COMMON CHRONIC NEURODEGENERATIVE DISEASES}

$A D$ is the most common cause of dementia, accounting for between $60-80 \%$ of cases. An estimated 5.8 million Americans of all ages are living with AD in $2019 .{ }^{4}$ It is a disease that develops over many years, occurring in slowly progressive stages before symptoms manifest. The two primary hallmark pathologies of $A D$ are amyloid- $\beta(A \beta)$ plaques, which are the extracellular accumulation of the $A \beta$ peptide, and neurofibrillary tangles (NFTs) composed of abnormally phosphorylated tau. ${ }^{5}$ These NFTs have been observed in the entorhinal cortex, the hippocampus, the amygdala, and the neocortex, with the degree of dementia correlating with the distribution of NFTs. ${ }^{6}$ Additionally, brain tissue from AD patients demonstrates the presence of activated microglia and astrocytes surrounding $A \beta$ plaques, as well as elevated cytokine levels, indicative of inflammation as a contributing factor in the development of the disease. 7,8

PD is the most common movement disorder and the second most common age-related neurodegenerative disorder after AD. An estimated one million Americans are thought to have PD, with nearly 60,000 newly diagnosed cases per year and thousands living undiagnosed. ${ }^{9}$ PD is characterized by the selective and progressive degeneration of dopamine (DA) producing neurons in an area deep in the brain known as the substantia nigra (SN). ${ }^{5}$ Loss of the neurotransmitter DA results in the classical clinical motor symptoms that include bradykinesia, rigidity, postural instability, and resting tremor. The remaining neurons in the SN typically contain proteinaceous inclusions, termed Lewy bodies, which have historically 
been thought to be mainly composed of alpha-synuclein and ubiquitin. ${ }^{10} \mathrm{~A}$ recent study, however, demonstrated that Lewy bodies are composed of a membranous medley rather than protein fibrils, which includes membrane fragments, lipids, and other cellular material. ${ }^{11}$ More recently, studying immune dysregulation in PD has attracted increased interest as activated microglia and T cells have been found in the SN of PD patients. ${ }^{12}$ Aside from the motor symptoms of PD, patients exhibit non-motor features years before clinical diagnosis, including a loss of smell, depression, anxiety, constipation, and the biggest predictor of PD in prodromal patients, rapid eye movement (REM) sleep behavior disorder (RBD). ${ }^{10}$ RBD is characterized by loss of REM sleep paralysis, allowing patients to "act out" dreams and represents the highest predictive value for PD, giving clinicians the ability to intervene early in the course of the disease before neuronal loss progresses past rescue and before symptomatic therapies confound assessments. ${ }^{13}$

ALS is the most common motor neuron (MN) disorder and the third most common adult-onset neurodegenerative disease after AD and PD. The ALS Association estimates the current prevalence of ALS is between 12,800 and 19,800 people in the United States. ${ }^{14}$ ALS is a progressive neurological disorder that affects both upper MNs (projecting from the cerebral cortex to the spinal cord) and lower MNs (projecting from the spinal cord to muscles). It is pathologically characterized by cytoplasmic inclusions of MNs primarily composed of ubiquitinated TDP-43 protein, except for patients with SOD1 or FUS mutations, in which case the main component of the inclusion bodies are SOD1 protein and FUS protein, respectively. ${ }^{15}$ Clinical features of the disease are mainly associated with motor dysfunction (muscle weakness, spasticity, and atrophy), but almost half of patients also develop cognitive and/or behavioral symptoms. ${ }^{15,16}$ Neuroinflammation has also been implicated in ALS as activated microglia and astrocytes are present in post-mortem tissue, and altered cytokine profiles have been reported. ${ }^{17}$

\section{CURRENT DRUG LANDSCAPE AND KINASES AS THE FUTURE}

Currently available drugs to treat $A D, P D$, and ALS target only symptoms and do not offer substantial benefit to patients, having modest effects at best. Only two types of medications have been approved by the FDA for treating cognitive symptoms of AD: cholinesterase inhibitors and the N-methyl$D$-aspartate receptor agonist memantine. To date, five drugs have been approved for the treatment of $A D$, and since 2003 no new drugs have been approved, with most failed drugs focused on targeting $A \beta$ accumulation. ${ }^{18}$ Late in 2019 Biogen announced that they were applying for FDA marketing approval of their anti-amyloid human monoclonal antibody known as aducanumab. Aducanumab, which selectively binds to $A \beta$ fibrils and soluble oligomers, demonstrated substantial reduction of $A \beta$ plaques in a dose- and time-dependent manner, such that after 12 months nearly half the patients who received the $10 \mathrm{mg} / \mathrm{kg}$ dose no longer had positive amyloid PET scans. ${ }^{19}$

Levodopa (L-DOPA), a precursor of DA, has been the most effective drug for treating the motor symptoms of PD but has increasingly negative side effects as the disease progresses. Other FDA approved treatments for PD are predominantly focused on increasing or substituting for low levels of DA to manage tremors and irregular movements: DA agonists directly stimulate the DA receptors, monoamine oxidase $B$ inhibitors prolong DA stimulation by decreasing DA breakdown, and catechol-O-methyl transferase inhibitors delay the breakdown of L-DOPA. ${ }^{10}$ Non-dopaminergic treatments include anticholinergics, adenosine $2 \mathrm{~A}$ antagonists, and a drug that is reported to act via multiple mechanisms to exert antiParkinsonian effects (amantadine). ${ }^{20}$ These FDA-approved drugs can be used as alternatives to L-DOPA, in addition to L-DOPA, or in combination with one another. Patients with advanced PD, who are unresponsive to drug treatment can alternatively be treated with deep brain stimulation to control motor symptoms. ${ }^{21}$

Treatments for ALS focus on managing symptoms through physiotherapy, nutrition, and respiratory support. The three FDA approved medications, two of which are different formulations of the same active agent, are only mildly effective at prolonging survival and are often taken in combination with symptomatic treatments. Since the first approved drug was hypothesized to modulate glutamate 
transmission, a vast majority of compounds tested in the past couple of decades have been antiglutamatergic but have not been successful. Other attempts have been made to reduce inflammation and oxidation, but most compounds have failed to demonstrate efficacy in human trials. ${ }^{22}$

In spite of the ability of the biomedical research community to turn kinase inhibitors into approved medicines, we believe this target tractability has not been exploited to the degree possible in neuroscience. By January 2020, the FDA had approved 55 small molecule protein kinase inhibitors and 53 of them are orally effective. The data collected around those 55 supports that 48 of them are used in the treatment of neoplastic diseases, while 9 are employed in the treatment of non-malignancies such as glaucoma and rheumatoid arthritis, for example. Remarkably, 17 have found utility in the treatment of more than one disease, such as imatinib, which is approved for the treatment of eight disparate disorders. ${ }^{23}$ Kinases have been largely ignored in the neuroscience space in favor of targets specific to protein misfolding, RNA toxicity, or chemical messaging in the brain. As such, a kinase-targeting drug has not yet been approved to treat a neurological disorder. More than 15 human protein kinases have been described as phosphorylating tau, contributing to its stabilization and aggregation through phosphorylation, while others, including PDK1, PERK and GCN2, regulate amyloid precursor protein processing and protein synthesis. ${ }^{24,25}$ LRRK2 and PINK1 are two kinases that are mutated in PD and have garnered attention as putative PD drug targets. ${ }^{26}$ Recent disclosures of TBK1 and NEK1 as geneticallyassociated ALS kinases highlight the important role of kinases in ALS etiology. ${ }^{27,}{ }^{28}$ Furthermore, rapamycin, a kinase-targeting drug that enhances autophagy, was advanced to phase II for treatment of ALS. $^{29}$

Driven by increased knowledge surrounding the brain penetration of kinase inhibitors, attempts have been made to repurpose FDA-approved kinase inhibitors for neurodegenerative diseases, but this strategy has not been successful. ${ }^{30}$ The majority of CNS-penetrant kinase inhibitors were optimized for systemic exposure rather than for CNS applications. ${ }^{31}$ Examples of well-studied kinases being pursued through drug repurposing are ABL1 for AD and PD (Nilotinib, Saracatinib, K0706, and Bosutinib), GSK3B for $A D$ and PD (Tideglusib and Neu-120), MAPK14 for AD (Neflamapimod), KIT for AD and ALS (Masitinib), MLK1-3 for PD (CEP-1347), and ROCK2 for ALS (Fasudil). ${ }^{31-33}$ These drugs may be acting through their primary target or an off-target kinase. Saracatinib, for example, has been pursued in the case of AD due to its off-target FYN inhibition rather than ABL1 inhibition. ${ }^{34}$ Only two drugs, Masitinib for AD and ALS, and CEP-1347 for PD, made it as far as Phase III, while the rest stalled or are still being investigated (https://clinicaltrials.gov).

Many kinase-targeting small molecule drugs approved for oncology are known to potently inhibit several kinase targets and exhibit poor kinome-wide selectivity. High-quality chemical tools (potent, cellactive, narrow spectrum of kinase activity) targeting human kinases are not easy to design or identify. Given the high homology among binding sites, human kinase inhibitors require years of expert medicinal chemistry to optimize in terms of potency and selectivity. Further complications arise from the abundance of poorly characterized inhibitors in the literature and commercially available compounds that falsely advertise their quality. High-quality chemical probes offer dynamic, reversible and tunable perturbations of biomolecular functions or interactions and, importantly, serve as potential leads for drug development. While a high-quality chemical probe will require additional optimization to be used as an effective CNStargeting agent, these small molecules represent impactful tools that can be used to validate novel targets and disease models as well as to characterize disease-propagating pathways for the first time.

\section{A SUBSET OF UNDERSTUDIED KINASES LINKED TO NEURODEGENERATION}


The majority of kinase-based research has historically focused on a subset of the human kinome, resulting in $\sim 80 \%$ of kinases being overlooked..$^{35}$ We refer to this portion of the kinome as understudied. While there are many ways to characterize the understudied nature of a kinase, we rely on the number of publications as one key measure to define this subset. For the purposes of this review, an understudied kinase has $<66$ PubMed citations on the human form of the kinase as of December 2019. This publication count was generated using the PubMed Gene database and searching for papers that are associated only with the human form of each kinase. The IDG program also uses publication count as one method to define their dark kinase list. PubMed citation count allowed us to characterize a set of 245 kinases (nearly half of the kinome) as understudied, 137 of which are also dark IDG kinases (Figure 1). We will continue to note whether a kinase is on the IDG list throughout the review.

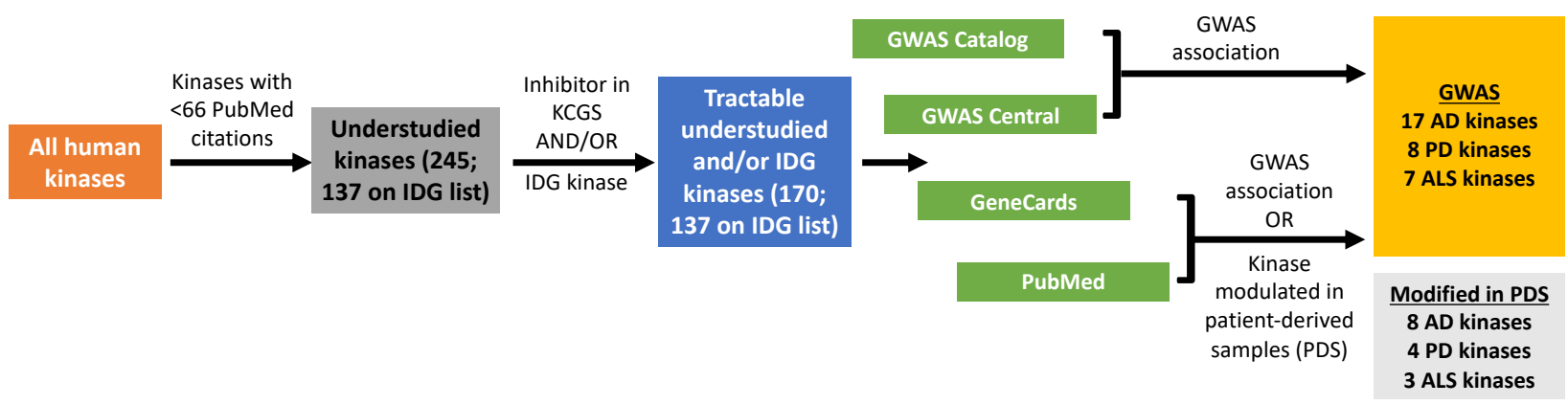

Figure 1. Workflow 1: Analysis of understudied kinases implicated in neurodegeneration.

This list of 245 kinases was then reduced by considering whether or not a kinase is currently tractable for drug discovery (known to bind a small molecule and potential for selectivity). Next in our analysis we checked to see if a narrow spectrum inhibitor was identified in the assembly of the kinase chemogenomic set (KCGS). KCGS was curated after a thorough examination of the data in the literature

Table 1. AD-linked kinase variants and disease implications.

\begin{tabular}{|c|c|c|c|c|}
\hline Kinase & Variant & Consequence & PubMed ID & IDG kinase \\
\hline ALPK2 & SNP & Increased susceptibility & 30617256 & Y \\
\hline ALPK3 & SNP & Unknown & 22005931 & Y \\
\hline BCKDK & SNP & Increased susceptibility & 29777097 & Y \\
\hline CAMK1D & SNP & Increased susceptibility of LOAD & 25649863 & Y \\
\hline CDK17 & Overexpression & Promoted AD neurodegeneration & 26885753 & Y \\
\hline CDK18 & Overexpression & Promoted AD neurodegeneration & 26885753 & Y \\
\hline EPHA6 & Copy number gain & Increased susceptibility of EO-FAD & 23752245 & $\mathrm{~N}$ \\
\hline INSRR & SNP & Increased susceptibility of LOAD & 30386171 & $\mathrm{~N}$ \\
\hline LMTK2 & Reduced expression & Reduced axonal transport & 31068217 & $\mathrm{Y}$ \\
\hline LRRK1 & SNP & Reduced abstract reasoning & 17903297 & $\mathrm{Y}$ \\
\hline MAPKAPK5 & Overexpression & Faster cognitive decline & 26080319 & $\mathrm{~N}$ \\
\hline MARK1 & Overexpression & Tau phosphorylation & 11089574 & $\mathrm{Y}$ \\
\hline MARK4 & SNP & Increased susceptibility & $30617256 ; 30979435$ & $\mathrm{Y}$ \\
\hline MAST4 & SNP & Reduced hippocampal volume & 28098162 & $\mathrm{Y}$ \\
\hline MINK1 & SNP & Increased susceptibility & 30413934 & $\mathrm{~N}$ \\
\hline NEK10 & SNP & Increased susceptibility of LOAD & 27770636 & $\mathrm{Y}$ \\
\hline NUAK1 & SNP & Increased cortical A levels & 23419831 & $\mathrm{~N}$ \\
\hline PIM3 & Overexpression & Increased susceptibility & 30349106 & $\mathrm{~N}$ \\
\hline SIK1 & SNP & Increased susceptibility of FAD & 26830138 & $\mathrm{~N}$ \\
\hline STK32B & SNP & Faster cognitive decline & $23535033 ; 30636644$ & $\mathrm{Y}$ \\
\hline STK32C & Increased methylation & Accelerated Braak stage progression & 30045751 & $\mathrm{Y}$ \\
\hline TAOK1 & Overexpression & Tau phosphorylation & $29730992 ; 23585562$ & $\mathrm{Y}$ \\
\hline TAOK2 & Overexpression & Tau phosphorylation & $29730992 ; 23585562$ & $\mathrm{Y}$ \\
\hline TNK1 & SNP & Increased susceptibility & $28631188 ; 18830724$ & $\mathrm{~N}$ \\
\hline TTBK1 & SNP & Increased susceptibility of LOAD & 21219968 & $\mathrm{Y}$ \\
\hline
\end{tabular}

LOAD: late-onset AD; EO-FAD: early-onset familial AD; FAD: familial AD as well as for the inhibitor sets at SGC-UNC. ${ }^{36}$ If an inhibitor was not identified via this exercise then we assume that currently only promiscuous inhibitors, if any, bind that particular kinase. Of note, an inhibitor that could not be shared without restrictions was also excluded from KCGS. A final consideration we applied for inclusion of kinases in this analysis is whether the kinases are screenable. To be considered screenable for our purposes, a commercial assay must be available to profile compounds for binding and/or inhibition. As an exception to this rule, all IDG kinases were kept on the list for further consideration. This step removed 75 kinases from consideration, 
Table 2. PD-linked kinase variants and disease implications.

\begin{tabular}{|c|c|c|c|c|}
\hline Kinase & Variant & Consequence & PubMed ID & IDG kinase \\
\hline AAK1 & SNP & Earlier age of onset & 19772629 & N \\
\hline BCKDK & SNP & Increased susceptibility & $28892059 ; 25064009$ & Y \\
\hline DSTYK & SNP & Increased susceptibility & 24842889 & Y \\
\hline LRRK1 & SNP & Increased susceptibility of LO-FPD & 24241507 & Y \\
\hline LTK & SNP & Increased susceptibility & 28892059 & Y \\
\hline MAP3K10 & Overactivation & Lewy body formation & 19332348 & Y \\
\hline MARK1 & Overactivation & Lewy body formation & 28522732 & Y \\
\hline PAK6 & Overactivation & Mediates LRRK2 toxicity & 26375402 & Y \\
\hline PKMYT1 & SNP & Increased susceptibility & 30348779 & Y \\
\hline SRMS & Overexpression & Faster progression & 29936662 & $\mathrm{~N}$ \\
\hline STK19 & SNP & Increased susceptibility of SPD/LO-PD & $24511991 ; 20711177$ & Y \\
\hline TNK1 & SNP & Faster cognitive decline & 22658654 & $\mathrm{~N}$ \\
\hline
\end{tabular}

LO-FPD: late-onset familial PD; SPD: sporadic PD; LO-PD: late-onset PD

Table 3. ALS-linked kinase variants and disease implications.

\begin{tabular}{|c|c|c|c|c|}
\hline Kinase & Variant & Consequence & PubMed ID & IDG kinase \\
\hline AAK1 & Decreased expression & Disregulated vesicle recycling & 25514244 & N \\
\hline CAMK1G & SNP & Increased susceptibility & 23624525 & Y \\
\hline CSNK1G3 & SNP & Increased survival & 19451621 & Y \\
\hline DYRK2 & SNP & C9orf72 mutation interaction & 22959728 & Y \\
\hline NEK1 & SNP & Increased susceptibility & 25700176 & Y \\
\hline PXK & SNP & Longer telomeres; longer survival & 30931641 & Y \\
\hline SCYL3 & SNP & Increased survival & 19451621 & Y \\
\hline STK36 & SNP & Increased association with ALS & 22959728 & Y \\
\hline TTBK1 & Overexpression & TDP-43 phosphorylation & 25473830 & Y \\
\hline TTBK2 & Overexpression & TDP-43 phosphorylation & 25473830 & Y \\
\hline
\end{tabular}
GWAS: https://www.ebi.ac.uk/gwas/ and https://www.gwascentral.org/. Next, the GeneCards human gene database was searched for all proteins tied to AD, PD, or ALS (https://www.genecards.org/). Any additional GWAS link that had not surfaced through searching the other two databases was noted and all publications associated with each kinase were reviewed, looking for GWAS first and patient-derived data next. Finally, a PubMed search was executed to identify any previously unidentified ties between each respective kinase and $A D, P D$, or ALS. GWAS were not extensively reviewed to determine the statistical significance of the implicated kinase, as an analysis of this type is beyond the scope of this review. The results of this analysis are captured in Figure 1, and in total 41 unique understudied kinases were linked to $A D, P D$ and/or ALS through this target triage methodology. Of note, 31 of these 41 unique kinases are on the IDG list. Figure 1 captures the endpoint of Workflow 1: a list of kinases implicated in disease based only on text mining. Additional workflows later in the review expand on and/or refine this output.

The consequences observed in patients due to changes in expression, increased copy number or epigenetic modification, overactivation or a single nucleotide polymorphism (SNP) have been collected and published. The specific disease-propagating clinical phenotypes are summarized in Tables 1-3 along with the literature reference from which it has been abstracted. While the clinical outcome that results from modulation of each kinase is captured, the specific mechanism(s) and pathway(s) by which it drives disease are often unknown and demand additional characterization if we hope to intervene therapeutically.

\section{KINASE EXPRESSION ANALYSES}


An interesting cross-examination is to compare publication count and expression of both understudied as well as well-studied kinases in a disease-relevant cell type. While expression is not the only determinant as to whether a kinase is significant in a disease, the complete absence of said kinase in a specific cell population diminishes its probable impact in driving disease pathology. The subset of understudied kinases defined for each respective disease as well as 5 well-studied kinases (Table 4) was plotted versus Table 4. Examples of well-studied kinases in AD, PD, and ALS.

publication

count (blue

bars) and RNA

expression

(orange lines)

for $A D, P D$, and

\begin{tabular}{|c|c|c|c|c|c|c|c|c|}
\hline AD kinases & $\begin{array}{c}\text { Publication } \\
\text { count }\end{array}$ & PubMed ID & PD kinases & $\begin{array}{c}\text { Publication } \\
\text { count }\end{array}$ & PubMed ID & ALS kinases & $\begin{array}{c}\text { Publication } \\
\text { count }\end{array}$ & PubMed ID \\
\hline GSK3A & 171 & 7704571 & STK39 & 85 & 21292315 & EPHA4 & 93 & 22922411 \\
\hline CDK5 & 352 & 16712493 & CDK5 & 352 & 9255390 & TBK1 & 306 & 30033073 \\
\hline NTRK1 & 354 & 8931004 & PINK1 & 357 & 16702191 & ERBB4 & 329 & 24119685 \\
\hline GSK3B & 1220 & 16470248 & LRRK2 & 880 & 29253086 & NTRK2 & 332 & 10786708 \\
\hline MAPK1 & 2087 & 8129042 & MAPK8 & 970 & 15696229 & CDK5 & 352 & 14673208 \\
\hline
\end{tabular}

ALS (Figures 3-

5). Kinases are oriented along the $x$-axis in order of increasing number of publications. As described previously, the publication count as of December 2019 was tabulated via searching for papers associated with the human form of each kinase using the PubMed Gene database.

Using the GEO DataSets repository (https://www.ncbi.nlm.nih.gov/gds/), we analyzed the specific

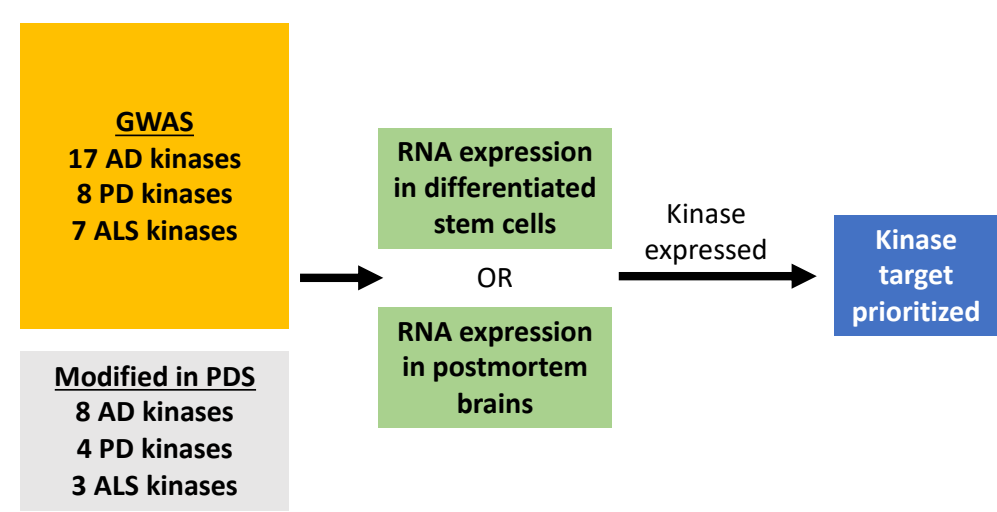

Figure 3. Workflow 2: Curation of kinases via expression analyses. brain regions and cell types that are impacted in chronic neurodegenerative diseases for their RNA expression of kinases identified via Workflow 1 (Figure 1). Workflow 2 (Figure 2) outlines the method by which we curated the kinase list generated from Workflow 1 via analyzing expression of these diseaseassociated kinases in disease-relevant cells. For AD, we opted to examine and summarize kinase expression in

microglia

AD kinase publication count versus expression

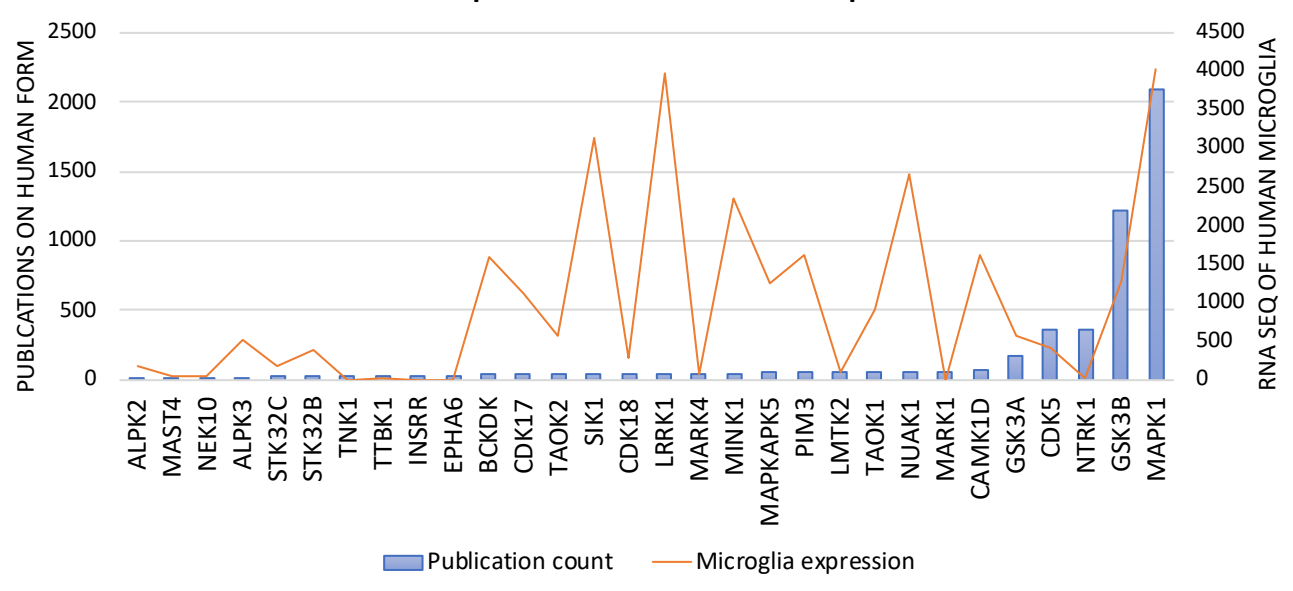

Figure 2. Publication count versus expression data for kinases implicated in AD.

derived from human induced pluripotent stem cells (iPSCs) donated by healthy volunteers and published as a bulk RNA sequencing dataset (GSE133432, Figure 3$).^{38}$ For $\mathrm{PD}$, we analyzed RNA sequencing data collected from human midbrain DA neurons from the ventral tegmental area and SN pars compacta of human post-mortem brains (GSE76514, Figure 4). ${ }^{39}$ For ALS, human single MNs from healthy volunteers were sequenced and RNA data plotted (GSE121069, Figure 5). ${ }^{40}$ 


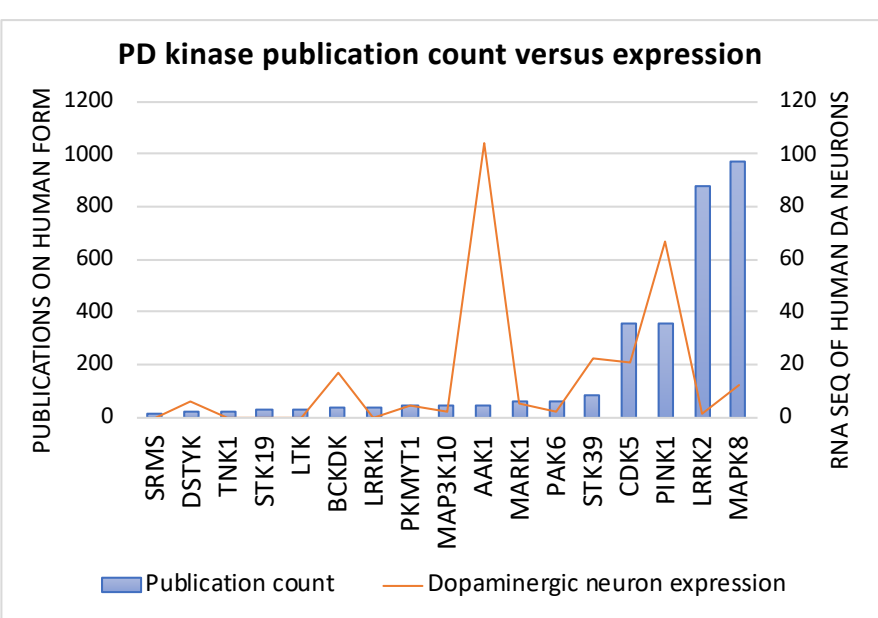

Figure 4. Publication count versus expression data for kinases implicated in PD.

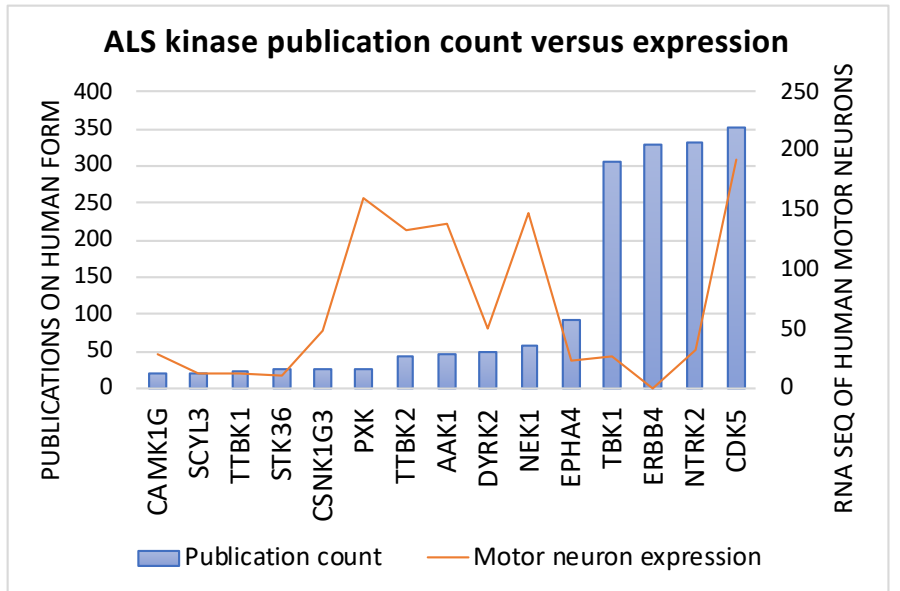

Figure 5. Publication count versus expression data for kinases implicated in ALS.

phase of neuroscience-focused kinase drug discovery.
Included in our study are some of the more studied kinases implicated in these same diseases. These kinases were identified using the GeneCards database. All proteins associated with a disease are given a significance score by the GeneCards website that roughly corresponds with how relevant and validated they are with respect to that specific disease. We selected the top five kinases on the list corresponding to each disease ranked with the highest significance scores (Table 4). The publication count as of December 2019 obtained through tabulating papers that reference the human kinase using the PubMed Gene database as well as the relevant representative publication linking the kinase to disease are also provided in Table 4. None of these well-studied kinases are on the IDG list.

Interestingly, examining the relationship between publication count (blue bars) and RNA expression (orange lines) as shown in Figures 3-5 clearly demonstrates that those kinases which have been focused on by the neurodegeneration field to date are not necessarily the most relevant from an expression standpoint. Workflow 2 (Figure 2) provides a method by which kinases implicated through mining patient genetic data can be refined prior to the experimental

\section{NEW TARGETS AND PRE-CLINICAL CANDIDATES FOR AD, PD, AND ALS}

This section focuses on kinases that are understudied, implicated in at least one chronic neurodegenerative disease, expressed in relevant cell type(s), and for which a narrow spectrum inhibitor has been identified. While patient-derived data has implicated these kinases in one or more neurodegenerative disorder, often more characterization has to be done to determine whether inhibition will elicit a positive outcome for patients. The lack of research on these kinases has also left many of them with few good chemical tools to study their biology, making KCGS an invaluable resource to learn more about their roles in neurodegeneration.

We have selected a subset of these kinases to highlight. Workflow 3 (Figure 6) outlines how we identify kinase inhibitors and the next steps once these inhibitors are selected. There are public databases and publications that harbor kinase screening data from which we can identify potential inhibitors and start to assess their selectivity/potency. If a kinase has not been screened previously, development of an assay that enables identification of inhibitors would be the first step in Workflow 3. The best available inhibitor(s) in terms of potency and selectivity across the kinome can then be advanced into a diseaserelevant assay to begin to determine if (1) the target is valid and (2) the compound can be considered a lead in the drug discovery pipeline. Selected output from Workflow 3 is captured in Table 5. Compounds 
include those from KCGS, the best available inhibitors that have been published but are not included in KCGS, and IDG DK (dark kinase) tools. As part of the IDG program, we confirm cellular penetration and potent $(<1 \mu \mathrm{M})$ target engagement of the kinase target before naming a compound a DK tool. The understudied nature of these kinases has resulted in only a few available chemical tools to further characterize their role in neurodegeneration. While these small molecules are not optimized for CNS applications, they represent a starting point for interrogating biological pathways that are aberrant in $A D$, PD, and/or ALS. Structures corresponding to compounds listed in Table 5 are shown in Figure 7 with their hinge-binding moieties oriented down in all cases. In accordance with our aspirational probe criteria, ${ }^{41}$ kinome-wide selectivity needs to be improved and activity in cells needs to be confirmed before any one of the molecules in Table 5 can be named a chemical probe for the target of interest. Important future work for the field is implementation of iterative medicinal chemistry optimization efforts to convert these narrow spectrum starting points into high-quality chemical probes. With high-quality probes available, the community will be able to interrogate the impact of inhibition in brain disease signaling. When moving beyond cell-based assays into animal models and eventually humans, blood-brain barrier penetrance will have to be assessed and improved via medicinal chemistry.

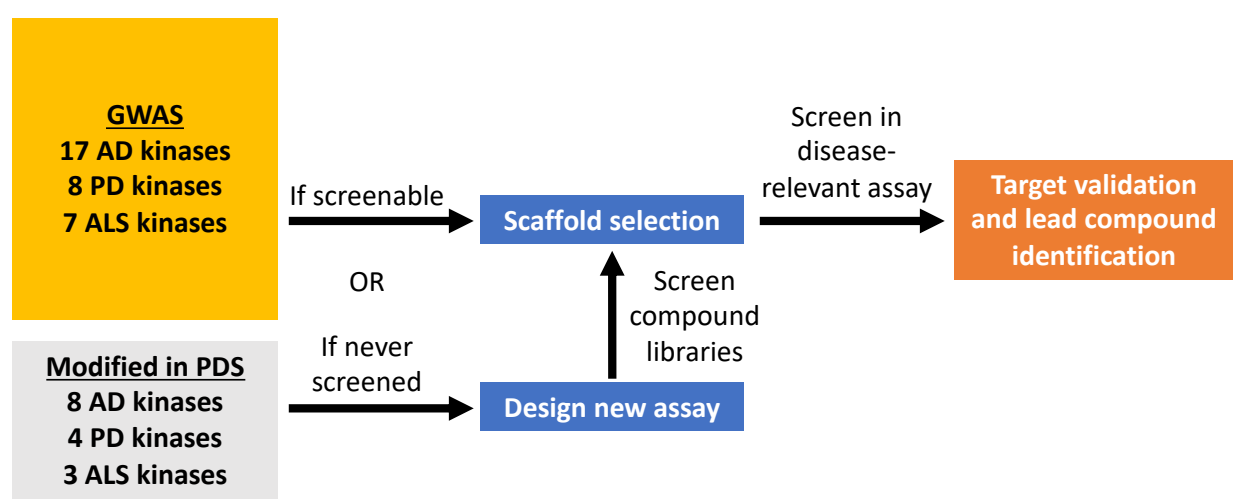

Figure 6. Workflow 3: Steps to validate kinase target and identify a small molecule to advance.

AAK1 is
inhibited by the 3-
acylaminoindazole
scaffold in KCGS. SGC-
AAK-1, in fact, was
recently identified as a
selective chemical
probe for studying
AAK1 biology and
released alongside a
structurally related
negative control
compound that does not inhibit AAK1. ${ }^{42,}{ }^{43}$ AAK1 expression is increased in PD patient brains and was correlated with age of onset in a GWAS (Table 2). ${ }^{56,57}$ The influence of AAK1 was suggested to rely on its essential role in endocytosis and lysosomal sorting, which, when aberrant, can contribute to the pathology of PD. ${ }^{56}$ AAK1 was shown to impact alpha-synuclein aggregation and resultant neurodegeneration in C. elegans, and its inhibition has been proposed to be therapeutically advantageous in the case of PD. ${ }^{58,59}$ In contrast, AAK1 protein levels were found to be decreased in ALS patients (Table 3). Furthermore, AAK1 was found to interact with mutant but not wild-type SOD1 in a yeast two-hybrid system and misdirected into aggregates containing mutant SOD1 and neurofilament proteins in rodent models of ALS. Dysfunction of AAK1 drives ALS pathology since its role is essential in the endosomal and synaptic vesicle recycling pathway. ${ }^{60}$ Further characterization of AAK1 with respect to ALS will determine whether inhibition is favorable in interrupting disease progression.

Table 5. Molecules that inhibit understudied kinases with AD, PD, and/or ALS implications.

\begin{tabular}{|c|c|c|c|c|}
\hline Kinase & AD, PD, ALS link & KCGS coverage & Literature compounds & DK tools \\
\hline AAK1 & GWAS PD and ALS PDS & SGC-AAK1-142, 43, UNC-AA-1-001743 & LP93550944 & Not IDG \\
\hline STK36 & GWAS ALS & GSK31287945 & - & - \\
\hline SIK1 & GWAS AD & GSK107091646 & AZ compound 3047 & Not IDG \\
\hline DYRK2 & GWAS ALS & BI0003683848 & EHT5372, 49,50 LY2857785, 51 & AZ-G53 \\
\hline NUAK1 & GWAS AD & HTH-01-015, WZ4003, XMD-17-5154 & Cephalon compound 5e L $^{55}$ & Not IDG \\
\hline
\end{tabular}


bioRxiv preprint doi: https://doi.org/10.1101/2020.04.01.020206; this version posted April 2, 2020. The copyright holder has placed this preprint (which was not certified by peer review) in the Public Domain. It is no longer restricted by copyright. Anyone can legally share, reuse, remix, or adapt this material for any purpose without crediting the original authors.

STK36 is an IDG kinase inhibited by a single compound in KCGS that was donated by GlaxoSmithKline. STK36 regulates the activity of GLI zinc-finger transcription factors, which impacts Hedgehog signaling, cell proliferation, and cell-fate specification. ${ }^{61}$ STK36 was a notable locus that showed increased evidence of association with ALS across 13 patient cohorts (Table 3 ). ${ }^{62}$ Given its role in regulating transcription, STK36 variants are thought to contribute to abnormal RNA transcription and processing in ALS. ${ }^{63}$ The impact of STK36 inhibition in the case of ALS can be interrogated further using the small molecule that we have described.

AAK1

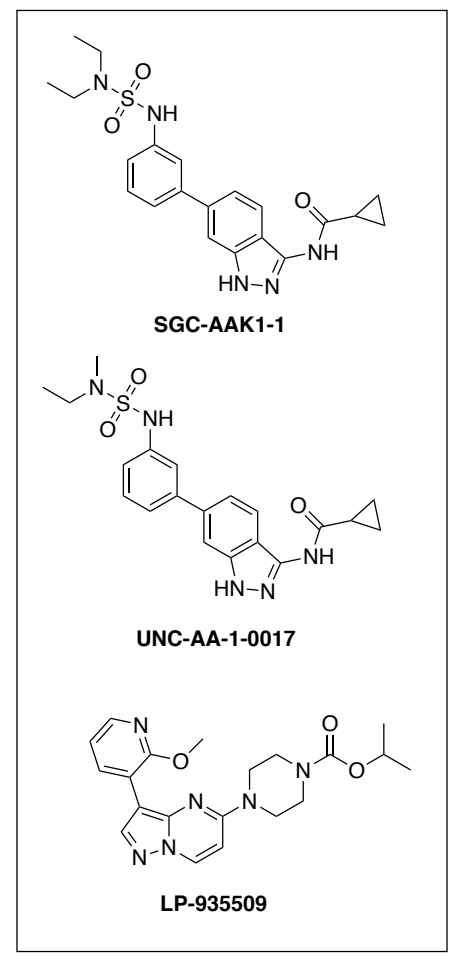

SIK1

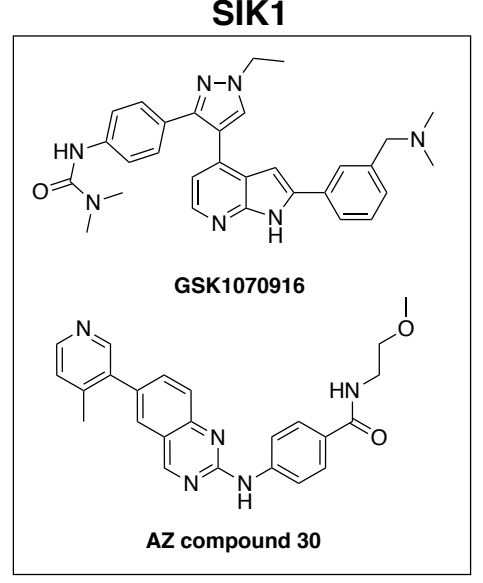

DYRK2<smiles>CCC(NC)C(=O)c1cc(C(C)=O)cc2c1C(=O)N2</smiles>

B100036838<smiles>CC(=O)Nc1cc(Nc2cc(NC3CC3)n3ncc(C#N)c3n2)ccc1N(C)CCN</smiles>

AZ-G<smiles>CC(C)c1c2cc(-c3ccnc(N[C@H]4CC[C@H](NC5CCOCC5)CC4)n3)ccc2nn1C</smiles>

LY2857785
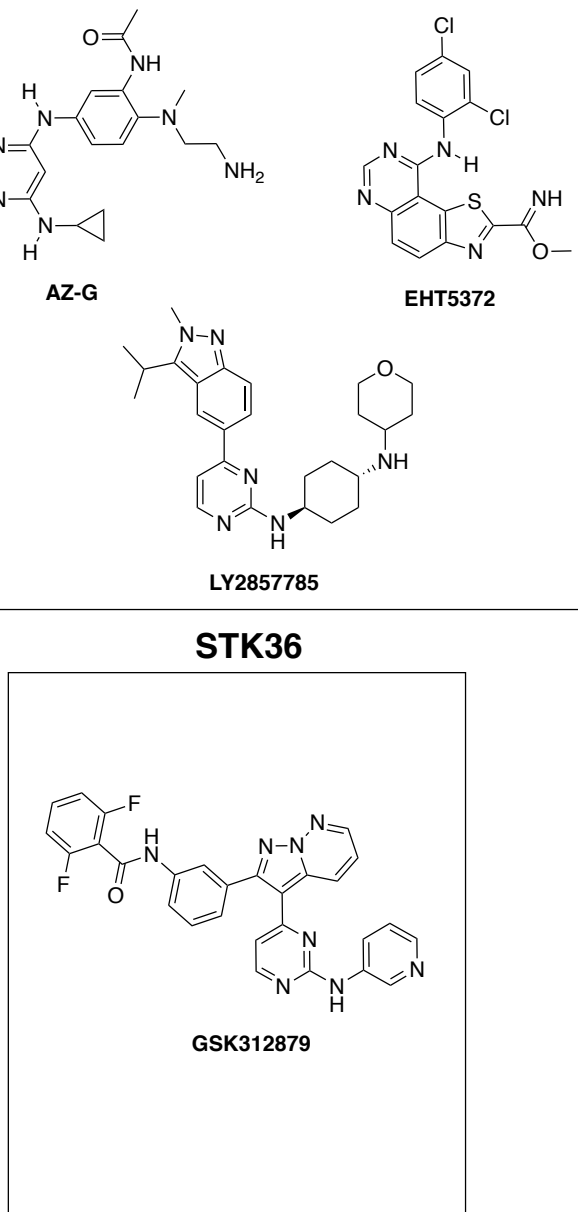

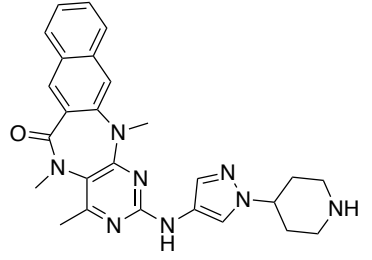

HTH-01-015

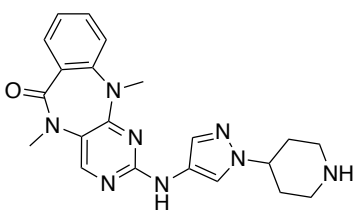

XMD-17-51

NUAK1

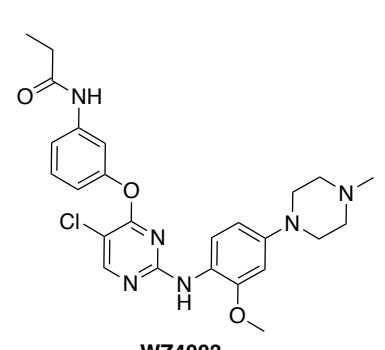

WZ4003

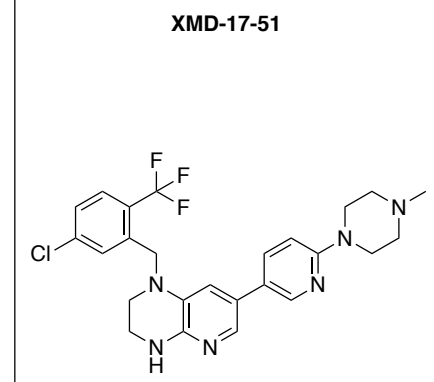

Cephalon compound 5e

Figure 7. Structures corresponding to narrow spectrum inhibitors of kinases listed in Table 5.

SIK1 is an understudied kinase inhibited by a single molecule in KCGS. A number of studies in the last decade have implicated SIK1 in brain pathology. ${ }^{64} \mathrm{~A}$ GWAS examining genes that contribute to AD age of onset identified SIK1 as a gene in close proximity to a SNP (Table 1). ${ }^{65}$ SIK1 did not achieve genomewide significance in this study. Importantly, significantly increased expression of SIK1 was observed in neutrophils taken from AD patients demonstrating dementia. ${ }^{66}$ It has been proposed that inhibition of 
SIK1 in pre-clinical mouse models of $A D$ results in reduced neuroinflammation. ${ }^{67}$ This finding is in alignment with the determination that SIK1 is crucial to regulating microglial apoptosis, especially given that microglial activation leads to neuroinflammation and is a hallmark of many neurodegenerative processes. ${ }^{64}$ Since neuroinflammation exacerbates $A D$, possibly leading to nerve cell death and synaptic dysfunction, inhibition of SIK1 would offer an attractive method to reduce this pathology-driving process.

DYRK2 is an IDG kinase inhibited by a single molecule in KCGS. We prepared a small library of pyrazolopyrimidines based upon a literature compound that was reported to have DYRK2 activity..$^{53}$ We profiled this library using the cell-based DYRK2 nanoBRET assay ${ }^{68}$ and we were able to identify AZ-G as meeting the criteria to be named a DK tool for DYRK2 $\left(I_{50}=160 \mathrm{nM}\right)$. Details about the DYRK2 nanoBRET assay and DK tool can be found at https://darkkinome.org/kinase/DYRK2. DYRKs are a family of conserved kinases that play key roles in the regulation of cell differentiation, proliferation, and survival. ${ }^{69}$ DYRK2 has been associated with ALS via GWAS. A genomic region that correlates with DYRK2 was identified as impacting the age of onset of ALS (Table 3). ${ }^{62}$ Additional studies are required to determine whether pharmacological inhibition of DYRK2 is advantageous in the case of ALS. DYRK2 has also been shown to phosphorylate tau in vitro on a residue that is hyperphosphorylated in filamentous tau from AD brains. ${ }^{70}$ This suggests that inhibition of DYRK2 may be therapeutically beneficial for AD.

NUAK1 is inhibited by three KCGS molecules. This kinase is highly expressed early in the developing brain. ${ }^{71}$ NUAK1 was reported as a biomarker for AD in a GWAS (Table 1). Through assessment of $A \beta$ levels in vivo via PET imaging, NUAK1 was associated with quantitative global $A \beta$ loading. ${ }^{72}$ Furthermore, NUAK1 was found in parallel cell-based and Drosophila genetic screens to regulate tau levels. Inhibition of NUAK1 in fruit flies suppressed neurodegeneration in tau-expressing Drosophila and NUAK1 haploinsufficiency rescued the phenotypes of a tauopathy mouse model. ${ }^{73}$ These cell and animal models point to NUAK1 inhibition as a potentially beneficial strategy in treating AD.

\section{PATH FORWARD}

We have identified kinases that are implicated in $A D, P D$, and/or ALS due to mutations, differential epigenetic processing, enhanced activation, or altered expression in patients. The clinical outcome of these changes, such as earlier onset of disease or prolonged life span, has been established in most cases (Tables 1-3). Relevant data that is missing is how modulating the kinase impacts disease-propagating pathways. Studying neurodegenerative disorders has proved to be challenging in the past due to the inaccessibility of human cells from individuals affected by the disease, with post-mortem tissue only providing a snapshot of the final stage of the disease. While immortalized cells lines and animal models have greatly increased our understanding of key biochemical pathways implicated in the pathogenesis of the disease, they fail to truly model the disease observed in humans as there are considerable differences between cell lines and between species in terms of protein expression levels, signaling pathways, and cellular processes. ${ }^{74-76}$ This gap in translation may be one of many reasons why hundreds of clinical trials for neurodegenerative treatments have failed in the past couple of decades. ${ }^{18,22,77}$ iPSCs offer the capability to generate specific patient-derived neural subtypes, with CRISPR-Cas9 technology allowing for the genetic modification of these cells. ${ }^{78}$ Since neurodegenerative diseases are highly complex, with many different cell types and regions involved, 3D cultures are a step forward in attempting to reproduce the multidimensional environment of the brain and hold an immense potential for modeling neurodegenerative diseases. ${ }^{74}$ Figure 8 highlights the entire process from patient to drug, highlighting the enabling technologies of iPSCs combined with CRISPR-Cas9 to both model disease and discover/test new therapeutics.

This system can be used to determine the results of kinase knockout or acute inhibition and bridge the gap between a novel kinase target and observed patient phenotype. The phenotype that results from acutely inhibiting one of these kinases may differ from what is observed due to chronic genetic knockout. Recent studies have revealed that genetic compensation in response to gene knockout can explain the 
different results obtained by acute and chronic gene inhibition. ${ }^{79} 80$ Importantly, studies of this type will help determine whether inhibition is a therapeutically beneficial strategy for each kinase tested.

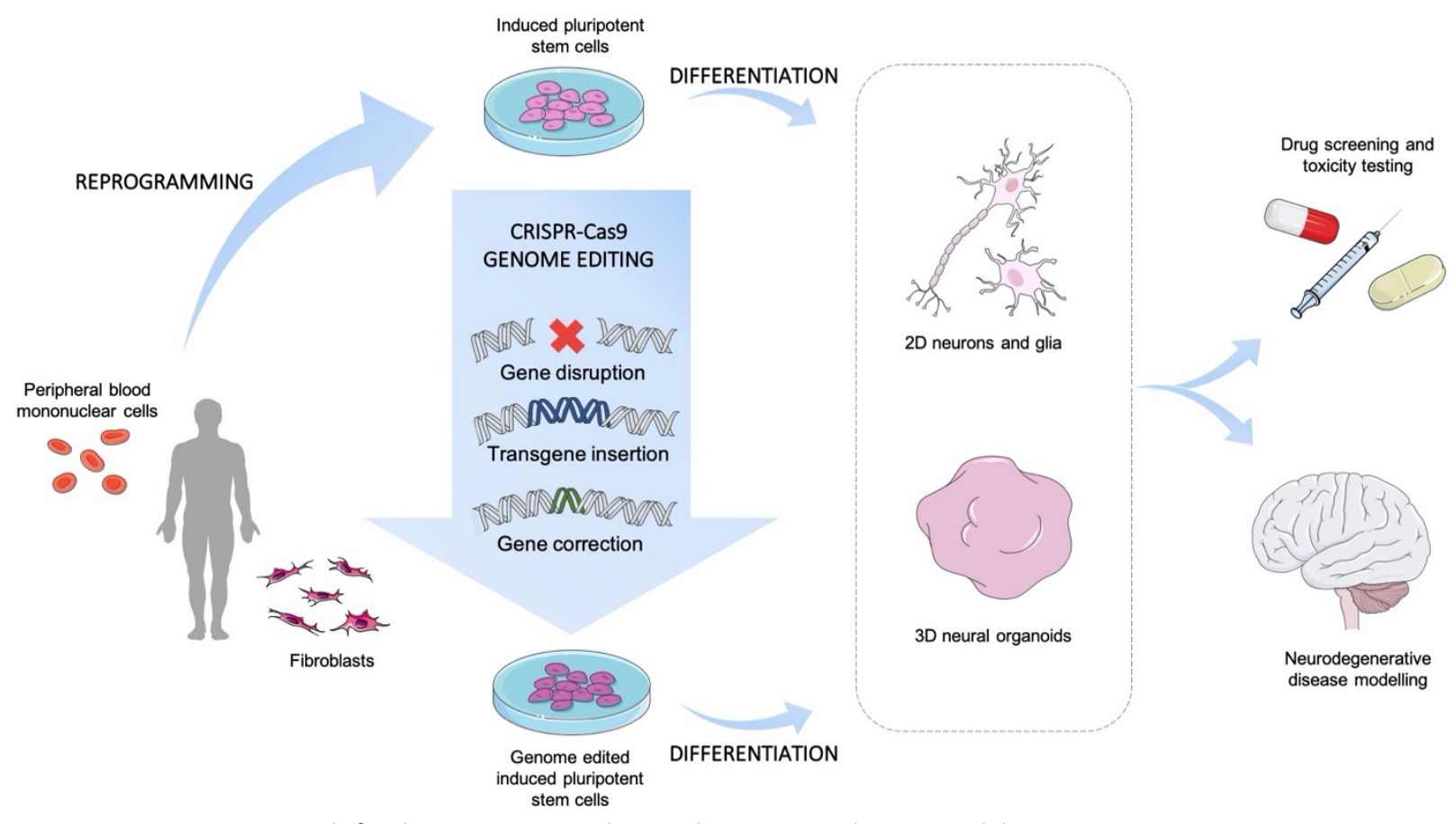

Figure 8. Human iPSCs as tools for drug screening and neurodegenerative disease modeling.

An aspirational goal is to develop small molecules for all kinases that have interesting biology related to $A D, P D$, and/or ALS but for which good chemical starting points do not currently exist or are in very early stages of development. Here we share some examples of kinases in this category that deserve medicinal chemistry lead discovery effort. NEK1 is an IDG kinase in need of a good chemical tool to enable its study. ${ }^{81}$ NEK1 variants confer susceptibility to ALS. Significant association was identified between lossof-function NEK1 variants and familial ALS risk (Table 3 ). ${ }^{28}$ The fact that loss-of-function is causative makes NEK1 a special case, where restoration rather than inhibition of its cellular role is required. TTBK1 and TTBK2 are two CK1 family kinases that are both IDG targets without good inhibitors described. SNPs in the TTBK1 gene have been associated with late-onset AD. Specific polymorphisms were found to decrease the risk of late-onset AD in multiple patient populations (Table 1). ${ }^{82}$ Abundant expression of TTBK1 in the cortical and hippocampal neurons of $A D$ brains, coupled with its confirmed role of phosphorylating tau and leading to pre-tangles, suggests that TTBK1 inhibitors would be therapeutically beneficial to AD patients. ${ }^{83}$ Furthermore, both TTBK1 and TTBK2 co-localize with TDP-43 inclusions in the ALS spinal cord and, thus, could represent attractive targets for therapeutic intervention for ALS (Table 3). ${ }^{84}$

TAOK1 and TAOK2 are understudied IDG kinases. Good molecules that inhibit the TAOKs are needed. TAOK1 and TAOK2 are phosphorylated and active in AD brain sections and they co-localize with both pre-tangle and tangle structures. TAOK inhibition was found to reduce tau phosphorylation in vitro and in cell models. ${ }^{85}$ Finally, STK19 is an IDG kinase that has been genetically implicated in PD via two separate GWAS but suffers from a lack of chemical inhibitors. The gene coding for STK19 was flagged as a highly significant locus with a strong association in sporadic PD (Table 2). ${ }^{86}$ An siRNA library screen highlighted that STK19 regulates levels of phosphorylated alpha-synuclein, implicating a role in the development of Lewy bodies and the pathology of PD. ${ }^{87}$ Further supporting its function in the brain, STK19 was also detected as a susceptibility gene for schizophrenia via GWAS. ${ }^{88}$ Dedicated medicinal chemistry efforts are required to develop good chemical tools to study these kinases. 
As part of our efforts to expand KCGS and increase its kinome-wide coverage in subsequent releases, we will develop narrow spectrum compounds that inhibit some of the neurodegenerationimplicated kinases discussed in this review that currently lack chemical coverage. We will also target several of these kinases through the IDG program, delivering cell-active DK tools to facilitate their biological characterization. Kinase inhibitors have proven useful for elucidation of the roles of particular kinases in signaling pathways and in the role these pathways play in disease. Importantly, this knowledge has led to more than 50 FDA-approved medicines that help patients. In spite of this success, it is surprising that much of the kinome remains unexplored. The lack of good chemical tools limits our ability to realize the value of understudied kinases. This is especially true for the neural kinome. We have highlighted the potential of targeting kinases expressed in the brain and implicated in neurodegeneration for the treatment of $A D, P D$, and $A L S$, and provided workflow that could offer insight into their biology. $A$ concerted community-wide effort is required to illuminate the impact of these understudied neural kinases on disease-propagating pathways in the brain. Illumination will most effectively be realized if research is done collaboratively and in the open, sharing our findings in real time with the research community at large.

\section{AUTHOR INFORMATION \\ Corresponding Author}

Alison D. Axtman - Structural Genomics Consortium, UNC Eshelman School of Pharmacy, University of North Carolina at Chapel Hill, Chapel Hill, NC, 27599, USA; Division of Chemical Biology and Medicinal Chemistry, UNC Eshelman School of Pharmacy, University of North Carolina at Chapel Hill, Chapel Hill, NC, 27599, USA; orcid.org/0000-0003-4779-9932; Phone: 919-962-5349; Email: alison.axtman@unc.edu

\section{Authors}

Andrea I. Krahn - Early Drug Discovery Unit, Montreal Neurological Institute-Hospital, McGill University, Montreal, QC, Canada, H3A 2B4; orcid.org/0000-0002-7975-6489

Carrow Wells - Structural Genomics Consortium, UNC Eshelman School of Pharmacy, University of North Carolina at Chapel Hill, Chapel Hill, NC, 27599, USA; Division of Chemical Biology and Medicinal Chemistry, UNC Eshelman School of Pharmacy, University of North Carolina at Chapel Hill, Chapel Hill, NC, 27599; orcid.org/0000-0003-4779-6792

David H. Drewry - Structural Genomics Consortium, UNC Eshelman School of Pharmacy, University of North Carolina at Chapel Hill, Chapel Hill, NC, 27599, USA; Division of Chemical Biology and Medicinal Chemistry, UNC Eshelman School of Pharmacy, University of North Carolina at Chapel Hill, Chapel Hill, NC, 27599; orcid.org/0000-0001-5973-5798

Lenore K. Beitel - Early Drug Discovery Unit, Montreal Neurological Institute-Hospital, McGill University, Montreal, QC, Canada, H3A 2B4; orcid.org/0000-0002-2836-5568

Thomas M. Durcan - Early Drug Discovery Unit, Montreal Neurological Institute-Hospital, McGill University, Montreal, QC, Canada, H3A 2B4; orcid.org/0000-0003-3942-1956

\section{Author Contributions}

A.D.A. and D.H.D. conceived the idea. A.D.A conducted literature review and drafted the manuscript. D.H.D., C.W., and A.D.A. identified promising kinase inhibitor scaffolds. A.I.K. and T.D. contributed to writing the manuscript. All authors contributed to critical editing and preparation of the final draft. All authors read and approved the final manuscript.

\section{Funding}

The Structural Genomics Consortium is a registered charity (number 1097737) that receives funds from AbbVie, Bayer Pharma AG, Boehringer Ingelheim, Canada Foundation for Innovation, Eshelman Institute 
for Innovation, Genome Canada, Genentech, Innovative Medicines Initiative (EU/EFPIA) [ULTRA-DD grant no. 115766], Janssen, Merck KGaA Darmstadt Germany, MSD, Novartis Pharma AG, Ontario Ministry of Economic Development and Innovation, Pfizer, São Paulo Research Foundation-FAPESP [2013/50724-5, 2014/5087-0 and 2016/17469-0], Takeda, and Wellcome [106169/ZZ14/Z]. A.D.A., D.H.D. and C.W. acknowledge U24DK116204 for support. A.D.A. and C.W. acknowledge ALSA Investigator Initiated Starter Grant wa1127 and U54AG065187 for support. T.M.D acknowledges the Ghislaine and Sebastian Van Berkom foundation and McGill Healthy Brains for Healthy Lives for funding support.

\section{Notes}

The authors declare no competing financial interest.

\section{ABBREVIATIONS}

CNS, central nervous system; KCGS, kinase chemogenomic set; FDA, Food and Drug Administration; AD, Alzheimer's disease; SGC, Structural Genomics Consortium; PD, Parkinson's disease; ALS, amyotrophic lateral sclerosis; IDG, Illuminating the Druggable Genome; $A \beta$, amyloid- $\beta$; NFTs, neurofibrillary tangles; DA, dopamine; SN, substantia nigra; REM, rapid eye movement; RBD, REM sleep behavior disorder; MN, motor neuron; NMDA, N-methyl-D-aspartate; L-DOPA, Levodopa; GWAS, genome wide association study; PDS, patient-derived sample; SNP, single nucleotide polymorphism; iPSCs, induced pluripotent stem cells 


\section{REFERENCES}

1. Schwartz, M., and Deczkowska, A. (2016) Neurological disease as a failure of brain-immune crosstalk: the multiple faces of neuroinflammation, Trends Immunol 37, 668-679.

2. Arneric, S. P., Kern, V. D., and Stephenson, D. T. (2018) Regulatory-accepted drug development tools are needed to accelerate innovative CNS disease treatments, Biochem Pharmacol 151, 291-306.

3. Carter, A. J., Kraemer, O., Zwick, M., Mueller-Fahrnow, A., Arrowsmith, C. H., and Edwards, A. M. (2019) Target 2035: probing the human proteome, Drug Discov Today 24, 2111-2115.

4. Hebert, L. E., Weuve, J., Scherr, P. A., and Evans, D. A. (2013) Alzheimer disease in the United States (2010-2050) estimated using the 2010 census, Neurology 80, 1778-1783.

5. Alzheimer's Association (2019) Alzheimer's disease facts and figures, Alzheimers Dement 15, 321-387.

6. Perl, D. P. (2010) Neuropathology of Alzheimer's disease, Mt Sinai J Med 77, 32-42.

7. Fakhoury, M. (2018) Microglia and astrocytes in Alzheimer's disease: implications for therapy, Curr Neuropharmacol 16, 508-518.

8. Morimoto, K., Horio, J., Satoh, H., Sue, L., Beach, T., Arita, S., Tooyama, I., and Konishi, Y. (2011) Expression profiles of cytokines in the brains of Alzheimer's disease (AD) patients compared to the brains of non-demented patients with and without increasing AD pathology, J Alzheimers Dis 25, 59-76.

9. Marras, C., Beck, J. C., Bower, J. H., Roberts, E., Ritz, B., Ross, G. W., Abbott, R. D., Savica, R., Van Den Eeden, S. K., Willis, A. W., Tanner, C. M., and on behalf of the Parkinson's Foundation, P. G. (2018) Prevalence of Parkinson's disease across North America, NPJ Parkinsons Dis 4, 21.

10. Balestrino, R., and Schapira, A. H. V. (2020) Parkinson disease, Eur J Neurol 27, 27-42.

11. Shahmoradian, S. H., Lewis, A. J., Genoud, C., Hench, J., Moors, T. E., Navarro, P. P., Castaño-Díez, D., Schweighauser, G., Graff-Meyer, A., Goldie, K. N., Sütterlin, R., Huisman, E., Ingrassia, A., Gier, Y. d., Rozemuller, A. J. M., Wang, J., Paepe, A. D., Erny, J., Staempfli, A., Hoernschemeyer, J., Großerüschkamp, F., Niedieker, D., El-Mashtoly, S. F., Quadri, M., Van Ijcken, W. F. J., Bonifati, V., Gerwert, K., Bohrmann, B., Frank, S., Britschgi, M., Stahlberg, H., Van de Berg, W. D. J., and Lauer, M. E. (2019) Lewy pathology in Parkinson's disease consists of crowded organelles and lipid membranes, Nat Neurosci 22, 1099-1109.

12. Baird, J. K., Bourdette, D., Meshul, C. K., and Quinn, J. F. (2019) The key role of T cells in Parkinson's disease pathogenesis and therapy, Parkinsonism Relat Disord 60, 25-31.

13. Postuma, R. B., Gagnon, J.-F., Bertrand, J.-A., Génier Marchand, D., and Montplaisir, J. Y. (2015)

Parkinson risk in idiopathic REM sleep behavior disorder: preparing for neuroprotective trials, Neurology 84, 1104-1113.

14. Mehta, P., Kaye, W., Raymond, J., Wu, R., Larson, T., Punjani, R., Heller, D., Cohen, J., Peters, T., Muravov, O., and Horton, K. (2018) Prevalence of amyotrophic lateral sclerosis - United States, 2014, MMWR Morb Mortal Wkly 67, 216-218.

15. Grad, L. I., Rouleau, G. A., Ravits, J., and Cashman, N. R. (2017) Clinical spectrum of amyotrophic lateral sclerosis (ALS), Cold Spring Harb Perspect Med 7.

16. Hardiman, O., Al-Chalabi, A., Chio, A., Corr, E. M., Logroscino, G., Robberecht, W., Shaw, P. J., Simmons, Z., and van den Berg, L. H. (2017) Amyotrophic lateral sclerosis, Nat Rev Dis Primers 3, 17071. 17. Zhao, W., Beers, D. R., and Appel, S. H. (2013) Immune-mediated mechanisms in the pathoprogression of amyotrophic lateral sclerosis, J Neuroimmune Pharmacol 8, 888-899.

18. Panza, F., Lozupone, M., Logroscino, G., and Imbimbo, B. P. (2019) A critical appraisal of amyloidbeta-targeting therapies for Alzheimer disease, Nat Rev Neurol 15, 73-88.

19. Schneider, L. (2020) A resurrection of aducanumab for Alzheimer's disease, The Lancet Neurol19, 111-112.

20. Staničová, J., Miškovsky, P., and Šutiak, V. (2001) Amantadine: an antiviral and antiparkinsonian agent, Vet Med - Czech 46, 244-256.

21. Elkouzi, A., Vedam-Mai, V., Eisinger, R. S., and Okun, M. S. (2019) Emerging therapies in Parkinson disease - repurposed drugs and new approaches, Nat Rev Neurol 15, 204-223. 
22. Mejzini, R., Flynn, L. L., Pitout, I. L., Fletcher, S., Wilton, S. D., and Akkari, P. A. (2019) ALS genetics, mechanisms, and therapeutics: where are we now?, Front Neurosci 13, 1310.

23. Roskoski, R., Jr. (2020) Properties of FDA-approved small molecule protein kinase inhibitors: A 2020 update, Pharmacological Res 152, 104609.

24. Martin, L., Latypova, X., Wilson, C. M., Magnaudeix, A., Perrin, M. L., Yardin, C., and Terro, F. (2013) Tau protein kinases: involvement in Alzheimer's disease, Ageing Res Rev 12, 289-309.

25. Flight, M. H. (2013) New kinase targets for Alzheimer's disease, Nat Rev Drug Discov 12, 739.

26. Nishioka, K., Kefi, M., Jasinska-Myga, B., Wider, C., Vilarino-Guell, C., Ross, O. A., Heckman, M. G., Middleton, L. T., Ishihara-Paul, L., Gibson, R. A., Amouri, R., Ben Yahmed, S., Ben Sassi, S., Zouari, M., El Euch, G., Farrer, M. J., and Hentati, F. (2010) A comparative study of LRRK2, PINK1 and genetically undefined familial Parkinson's disease, J Neurol Neurosurg Psychiatry 81, 391-395.

27. Oakes, J. A., Davies, M. C., and Collins, M. O. (2017) TBK1: a new player in ALS linking autophagy and neuroinflammation, Mol Brain 10, 5.

28. Kenna, K. P., van Doormaal, P. T., Dekker, A. M., Ticozzi, N., Kenna, B. J., Diekstra, F. P., van Rheenen, W., van Eijk, K. R., Jones, A. R., Keagle, P., Shatunov, A., Sproviero, W., Smith, B. N., van Es, M. A., Topp, S. D., Kenna, A., Miller, J. W., Fallini, C., Tiloca, C., McLaughlin, R. L., Vance, C., Troakes, C., Colombrita, C., Mora, G., Calvo, A., Verde, F., Al-Sarraj, S., King, A., Calini, D., de Belleroche, J., Baas, F., van der Kooi, A. J., de Visser, M., Ten Asbroek, A. L., Sapp, P. C., McKenna-Yasek, D., Polak, M., Asress, S., MunozBlanco, J. L., Strom, T. M., Meitinger, T., Morrison, K. E., Lauria, G., Williams, K. L., Leigh, P. N., Nicholson, G. A., Blair, I. P., Leblond, C. S., Dion, P. A., Rouleau, G. A., Pall, H., Shaw, P. J., Turner, M. R., Talbot, K., Taroni, F., Boylan, K. B., Van Blitterswijk, M., Rademakers, R., Esteban-Perez, J., Garcia-Redondo, A., Van Damme, P., Robberecht, W., Chio, A., Gellera, C., Drepper, C., Sendtner, M., Ratti, A., Glass, J. D., Mora, J. S., Basak, N. A., Hardiman, O., Ludolph, A. C., Andersen, P. M., Weishaupt, J. H., Brown, R. H., Jr., AlChalabi, A., Silani, V., Shaw, C. E., van den Berg, L. H., Veldink, J. H., and Landers, J. E. (2016) NEK1 variants confer susceptibility to amyotrophic lateral sclerosis, Nature Genet 48, 1037-1042.

29. Mandrioli, J., D'Amico, R., Zucchi, E., Gessani, A., Fini, N., Fasano, A., Caponnetto, C., Chiò, A., Dalla Bella, E., Lunetta, C., Mazzini, L., Marinou, K., Sorarù, G., de Biasi, S., Lo Tartaro, D., Pinti, M., Cossarizza, A., and group, R.-A. i. (2018) Rapamycin treatment for amyotrophic lateral sclerosis: protocol for a phase II randomized, double-blind, placebo-controlled, multicenter, clinical trial (RAP-ALS trial), Medicine (Baltimore) 97, e11119-e11119.

30. Heffron, T. P. (2016) Small molecule kinase inhibitors for the treatment of brain cancer, J Med Chem 59, 10030-10066.

31. Shi, Y., and Mader, M. (2018) Brain penetrant kinase inhibitors: learning from kinase neuroscience discovery, Bioorg Med Chem Lett 28, 1981-1991.

32. Chico, L. K., Van Eldik, L. J., and Watterson, D. M. (2009) Targeting protein kinases in central nervous system disorders, Nat Rev Drug Discov 8, 892-909.

33. Rask-Andersen, M., Zhang, J., Fabbro, D., and Schioth, H. B. (2014) Advances in kinase targeting: current clinical use and clinical trials, Trends Pharmacol Sci 35, 604-620.

34. Nygaard, H. B., van Dyck, C. H., and Strittmatter, S. M. (2014) Fyn kinase inhibition as a novel therapy for Alzheimer's disease, Alzheimers Res Ther 6, 8.

35. Fedorov, O., Muller, S., and Knapp, S. (2010) The (un)targeted cancer kinome, Nat Chem Biol 6, 166169.

36. Wells, C. I., Hassan, A.-A., Andrews, D. M., Asquith, C. R. M., Axtman, A. D., Chung, M., Dikic, I., Ebner, D., Elkins, J. M., Ettmayer, P., Fischer, C., Frederiksen, M., Gray, N. S., Hatch, S., Knapp, S., Lee, S., Lücking, U., Michaelides, M., Mills, C. E., Müller, S., Owen, D., Picado, A., Ramadan, K., Saikatendu, K. S., Schröder, M., Stolz, A., Tellechea, M., Treiber, D. K., Turunen, B., Vilar, S., Wang, J., Zuercher, W. J., Willson, T. M., and Drewry, D. H. (2019) The kinase chemogenomic set (KCGS): an open science resource for kinase vulnerability identification, bioRxiv, 10.1101/2019.12.22.886523. 
37. King, E. A., Davis, J. W., and Degner, J. F. (2019) Are drug targets with genetic support twice as likely to be approved? Revised estimates of the impact of genetic support for drug mechanisms on the probability of drug approval, PLoS Genet 15, e1008489.

38. Hasselmann, J., Coburn, M. A., England, W., Figueroa Velez, D. X., Kiani Shabestari, S., Tu, C. H., McQuade, A., Kolahdouzan, M., Echeverria, K., Claes, C., Nakayama, T., Azevedo, R., Coufal, N. G., Han, C. Z., Cummings, B. J., Davtyan, H., Glass, C. K., Healy, L. M., Gandhi, S. P., Spitale, R. C., and BlurtonJones, M. (2019) Development of a chimeric model to study and manipulate human microglia in vivo, Neuron 103, 1016-1033.e1010.

39. Nichterwitz, S., Chen, G., Aguila Benitez, J., Yilmaz, M., Storvall, H., Cao, M., Sandberg, R., Deng, Q., and Hedlund, E. (2016) Laser capture microscopy coupled with Smart-seq2 for precise spatial transcriptomic profiling, Nat Commun 7, 12139-12139.

40. Nijssen, J., Aguila, J., Hoogstraaten, R., Kee, N., and Hedlund, E. (2018) Axon-seq decodes the motor axon transcriptome and its modulation in response to ALS, Stem Cell Rep 11, 1565-1578.

41. Asquith, C. R. M., Berger, B.-T., Wan, J., Bennett, J. M., Capuzzi, S. J., Crona, D. J., Drewry, D. H., East, M. P., Elkins, J. M., Fedorov, O., Godoi, P. H., Hunter, D. M., Knapp, S., Müller, S., Torrice, C. D., Wells, C. I., Earp, H. S., Willson, T. M., and Zuercher, W. J. (2019) SGC-GAK-1: a chemical probe for cyclin G associated kinase (GAK), J Med Chem 62, 2830-2836.

42. Agajanian, M. J., Walker, M. P., Axtman, A. D., Ruela-de-Sousa, R. R., Serafin, D. S., Rabinowitz, A. D., Graham, D. M., Ryan, M. B., Tamir, T., Nakamichi, Y., Gammons, M. V., Bennett, J. M., Counago, R. M., Drewry, D. H., Elkins, J. M., Gileadi, C., Gildadi, O., Godoi, P. H., Kapadia, N., Muller, S., Santiago, A. S., Sorrell, F. J., Wells, C. I., Fedorov, O., Willson, T. M., Zuercher, W. J., and Major, M. B. (2019) WNT activates the AAK1 kinase to promote clathrin-mediated endocytosis of LRP6 and establish a negative feedback loop, Cell Rep 26, 79-83.

43. Wells, C., Couñago, R. M., Limas, J. C., Almeida, T. L., Cook, J. G., Drewry, D. H., Elkins, J. M., Gileadi, O., Kapadia, N. R., Lorente-Macias, A., Pickett, J. E., Riemen, A., Ruela-de-Sousa, R. R., Willson, T. M., Zhang, C., Zuercher, W. J., Zutshi, R., and Axtman, A. D. (2019) SGC-AAK1-1: a chemical probe targeting AAK1 and BMP2K, ACS Med Chem Lett 11, 340-345.

44. Kostich, W., Hamman, B. D., Li, Y.-W., Naidu, S., Dandapani, K., Feng, J., Easton, A., Bourin, C., Baker, K., Allen, J., Savelieva, K., Louis, J. V., Dokania, M., Elavazhagan, S., Vattikundala, P., Sharma, V., Das, M. L., Shankar, G., Kumar, A., Holenarsipur, V. K., Gulianello, M., Molski, T., Brown, J. M., Lewis, M., Huang, Y., Lu, Y., Pieschl, R., O'Malley, K., Lippy, J., Nouraldeen, A., Lanthorn, T. H., Ye, G., Wilson, A., Balakrishnan, A., Denton, R., Grace, J. E., Lentz, K. A., Santone, K. S., Bi, Y., Main, A., Swaffield, J., Carson, K., Mandlekar, S., Vikramadithyan, R. K., Nara, S. J., Dzierba, C., Bronson, J., Macor, J. E., Zaczek, R., Westphal, R., Kiss, L., Bristow, L., Conway, C. M., Zambrowicz, B., and Albright, C. F. (2016) Inhibition of AAK1 kinase as a novel therapeutic approach to treat neuropathic pain, J Pharmacol Exp Ther 358, 371386.

45. Gamo, F. J., Sanz, L. M., Vidal, J., de Cozar, C., Alvarez, E., Lavandera, J. L., Vanderwall, D. E., Green, D. V., Kumar, V., Hasan, S., Brown, J. R., Peishoff, C. E., Cardon, L. R., and Garcia-Bustos, J. F. (2010) Thousands of chemical starting points for antimalarial lead identification, Nature 465, 305-310. 46. Anderson, K., Lai, Z., McDonald, O. B., Stuart, J. D., Nartey, E. N., Hardwicke, M. A., Newlander, K., Dhanak, D., Adams, J., Patrick, D., Copeland, R. A., Tummino, P. J., and Yang, J. (2009) Biochemical characterization of GSK1070916, a potent and selective inhibitor of Aurora B and Aurora C kinases with an extremely long residence time, Biochem J 420, 259-265.

47. Vasbinder, M. M., Aquila, B., Augustin, M., Chen, H., Cheung, T., Cook, D., Drew, L., Fauber, B. P., Glossop, S., Grondine, M., Hennessy, E., Johannes, J., Lee, S., Lyne, P., Mortl, M., Omer, C., Palakurthi, S., Pontz, T., Read, J., Sha, L., Shen, M., Steinbacher, S., Wang, H., Wu, A., and Ye, M. (2013) Discovery and optimization of a novel series of potent mutant B-Raf(V600E) selective kinase inhibitors, J Med Chem 56, 1996-2015. 
48. Heckel, A., Roth, G. J., Kley, J., Hoerer, S., and Uphues, I. (2005) Novel alkyl-containing 5acylindolinones, their preparation and their use as pharmaceutical products (WIPO, Ed.), Boehringer Ingelheim International GMBH, Germany.

49. Foucourt, A., Hedou, D., Dubouilh-Benard, C., Girard, A., Taverne, T., Casagrande, A. S., Desire, L., Leblond, B., and Besson, T. (2014) Design and synthesis of thiazolo[5,4-f]quinazolines as DYRK1A inhibitors, part II, Molecules 19, 15411-15439.

50. Coutadeur, S., Benyamine, H., Delalonde, L., de Oliveira, C., Leblond, B., Foucourt, A., Besson, T., Casagrande, A. S., Taverne, T., Girard, A., Pando, M. P., and Desire, L. (2015) A novel DYRK1A (dual specificity tyrosine phosphorylation-regulated kinase $1 \mathrm{~A}$ ) inhibitor for the treatment of Alzheimer's disease: effect on Tau and amyloid pathologies in vitro, J Neurochem 133, 440-451.

51. Yin, T., Lallena, M. J., Kreklau, E. L., Fales, K. R., Carballares, S., Torrres, R., Wishart, G. N., Ajamie, R. T., Cronier, D. M., Iversen, P. W., Meier, T. I., Foreman, R. T., Zeckner, D., Sissons, S. E., Halstead, B. W., Lin, A. B., Donoho, G. P., Qian, Y., Li, S., Wu, S., Aggarwal, A., Ye, X. S., Starling, J. J., Gaynor, R. B., de Dios, A., and Du, J. (2014) A novel CDK9 inhibitor shows potent antitumor efficacy in preclinical hematologic tumor models, Mol Cancer Ther 13, 1442-1456.

52. De Antoni, A., Maffini, S., Knapp, S., Musacchio, A., and Santaguida, S. (2012) A small-molecule inhibitor of Haspin alters the kinetochore functions of Aurora B, J Cell Biol 199, 269-284.

53. Dowling, J. E., Alimzhanov, M., Bao, L., Chuaqui, C., Denz, C. R., Jenkins, E., Larsen, N. A., Lyne, P. D., Pontz, T., Ye, Q., Holdgate, G. A., Snow, L., O'Connell, N., and Ferguson, A. D. (2016) Potent and selective CK2 kinase inhibitors with effects on Wnt pathway signaling in vivo, ACS Med Chem Lett 7, 300-305.

54. Banerjee, S., Buhrlage, S. J., Huang, H. T., Deng, X., Zhou, W., Wang, J., Traynor, R., Prescott, A. R., Alessi, D. R., and Gray, N. S. (2014) Characterization of WZ4003 and HTH-01-015 as selective inhibitors of the LKB1-tumour-suppressor-activated NUAK kinases, Biochem J 457, 215-225.

55. Milkiewicz, K. L., Weinberg, L. R., Albom, M. S., Angeles, T. S., Cheng, M., Ghose, A. K., Roemmele, R. C., Theroff, J. P., Underiner, T. L., Zificsak, C. A., and Dorsey, B. D. (2010) Synthesis and structure-activity relationships of 1,2,3,4-tetrahydropyrido[2,3-b]pyrazines as potent and selective inhibitors of the anaplastic lymphoma kinase, Bioorg Med Chem 18, 4351-4362.

56. Latourelle, J. C., Pankratz, N., Dumitriu, A., Wilk, J. B., Goldwurm, S., Pezzoli, G., Mariani, C. B., DeStefano, A. L., Halter, C., Gusella, J. F., Nichols, W. C., Myers, R. H., Foroud, T., Progeni Investigators, C., Molecular Genetic, L., GenePd Investigators, C., and Molecular Genetic, L. (2009) Genomewide association study for onset age in Parkinson disease, BMC Med Genet 10, 98.

57. Zhang, Y., James, M., Middleton, F. A., and Davis, R. L. (2005) Transcriptional analysis of multiple brain regions in Parkinson's disease supports the involvement of specific protein processing, energy metabolism, and signaling pathways, and suggests novel disease mechanisms, Am J Med Genet $B$ Neurophyschiatr Genet 137b, 5-16.

58. Usenovic, M., Knight, A. L., Ray, A., Wong, V., Brown, K. R., Caldwell, G. A., Caldwell, K. A., Stagljar, I., and Krainc, D. (2012) Identification of novel ATP13A2 interactors and their role in $\alpha$-synuclein misfolding and toxicity, Human Mol Genet 21, 3785-3794.

59. Abdel-Magid, A. F. (2017) Inhibitors of adaptor-associated kinase 1 (AAK1) may treat neuropathic pain, schizophrenia, Parkinson's disease, and other disorders, ACS Med Chem Lett 8, 595-597. 60. Shi, B., Conner, S. D., and Liu, J. (2014) Dysfunction of endocytic kinase AAK1 in ALS, Int J Mol Sci 15, 22918-22932.

61. Murone, M., Luoh, S.-M., Stone, D., Li, W., Gurney, A., Armanini, M., Grey, C., Rosenthal, A., and de Sauvage, F. J. (2000) Gli regulation by the opposing activities of Fused and Suppressor of Fused, Nat Cell Biol 2, 310-312.

62. Ahmeti, K. B., Ajroud-Driss, S., Al-Chalabi, A., Andersen, P. M., Armstrong, J., Birve, A., Blauw, H. M., Brown, R. H., Bruijn, L., Chen, W., Chio, A., Comeau, M. C., Cronin, S., Diekstra, F. P., Soraya Gkazi, A., Glass, J. D., Grab, J. D., Groen, E. J., Haines, J. L., Hardiman, O., Heller, S., Huang, J., Hung, W. Y., 
Jaworski, J. M., Jones, A., Khan, H., Landers, J. E., Langefeld, C. D., Leigh, P. N., Marion, M. C., McLaughlin, R. L., Meininger, V., Melki, J., Miller, J. W., Mora, G., Pericak-Vance, M. A., Rampersaud, E., Robberecht, W., Russell, L. P., Salachas, F., Saris, C. G., Shatunov, A., Shaw, C. E., Siddique, N., Siddique, T., Smith, B. N., Sufit, R., Topp, S., Traynor, B. J., Vance, C., van Damme, P., van den Berg, L. H., van Es, M. A., van Vught, P. W., Veldink, J. H., Yang, Y., and Zheng, J. G. (2013) Age of onset of amyotrophic lateral sclerosis is modulated by a locus on 1p34.1, Neurobiol Aging 34, 357.e357-319.

63. Steinberg, K. M., Yu, B., Koboldt, D. C., Mardis, E. R., and Pamphlett, R. (2015) Exome sequencing of case-unaffected-parents trios reveals recessive and de novo genetic variants in sporadic ALS, Sci Rep 5, 9124.

64. Zhang, Y., Gao, W., Yang, K., Tao, H., and Yang, H. (2018) Salt-inducible kinase 1 (SIK1) is induced by alcohol and suppresses microglia inflammation via NF-KB signaling, Cell Physiol Biochem 47, 1411-1421. 65. Herold, C., Hooli, B. V., Mullin, K., Liu, T., Roehr, J. T., Mattheisen, M., Parrado, A. R., Bertram, L., Lange, C., and Tanzi, R. E. (2016) Family-based association analyses of imputed genotypes reveal genome-wide significant association of Alzheimer's disease with OSBPL6, PTPRG, and PDCL3, Mol Psychiatr 21, 1608-1612.

66. Dong, Y., Lagarde, J., Xicota, L., Corne, H., Chantran, Y., Chaigneau, T., Crestani, B., Bottlaender, M., Potier, M.-C., Aucouturier, P., Dorothée, G., Sarazin, M., and Elbim, C. (2018) Neutrophil hyperactivation correlates with Alzheimer's disease progression, Ann Neurol 83, 387-405.

67. Ozanne, J., Prescott, A. R., and Clark, K. (2015) The clinically approved drugs dasatinib and bosutinib induce anti-inflammatory macrophages by inhibiting the salt-inducible kinases, Biochem J 465, 271-279. 68. Vasta, J. D., Corona, C. R., Wilkinson, J., Zimprich, C. A., Hartnett, J. R., Ingold, M. R., Zimmerman, K., Machleidt, T., Kirkland, T. A., Huwiler, K. G., Ohana, R. F., Slater, M., Otto, P., Cong, M., Wells, C. I., Berger, B. T., Hanke, T., Glas, C., Ding, K., Drewry, D. H., Huber, K. V. M., Willson, T. M., Knapp, S., Muller, S., Meisenheimer, P. L., Fan, F., Wood, K. V., and Robers, M. B. (2017) Quantitative, wide-spectrum kinase profiling in live cells for assessing the effect of cellular ATP on target engagement, Cell Chem Biol 25, 206-214.

69. Becker, W. (2012) Emerging role of DYRK family protein kinases as regulators of protein stability in cell cycle control, Cell Cycle 11, 3389-3394.

70. Woods, Y. L., Cohen, P., Becker, W., Jakes, R., Goedert, M., Wang, X., and Proud, C. G. (2001) The kinase DYRK phosphorylates protein-synthesis initiation factor elF2Bepsilon at Ser539 and the microtubule-associated protein tau at Thr212: potential role for DYRK as a glycogen synthase kinase 3priming kinase, Biochem J 355, 609-615.

71. Bekri, A., Billaud, M., and Thelu, J. (2014) Analysis of NUAK1 and NUAK2 expression during early chick development reveals specific patterns in the developing head, Int J Dev Biol 58, 379-384.

72. Ramanan, V. K., Risacher, S. L., Nho, K., Kim, S., Swaminathan, S., Shen, L., Foroud, T. M., Hakonarson, H., Huentelman, M. J., Aisen, P. S., Petersen, R. C., Green, R. C., Jack, C. R., Koeppe, R. A., Jagust, W. J., Weiner, M. W., and Saykin, A. J. (2014) APOE and BCHE as modulators of cerebral amyloid deposition: a florbetapir PET genome-wide association study, Mol Psychiatr 19, 351-357.

73. Lasagna-Reeves, C. A., de Haro, M., Hao, S., Park, J., Rousseaux, M. W., Al-Ramahi, I., Jafar-Nejad, P., Vilanova-Velez, L., See, L., De Maio, A., Nitschke, L., Wu, Z., Troncoso, J. C., Westbrook, T. F., Tang, J., Botas, J., and Zoghbi, H. Y. (2016) Reduction of Nuak1 decreases Tau and reverses phenotypes in a tauopathy mouse model, Neuron 92, 407-418.

74. Mohamed, N. V., Larroquette, F., Beitel, L. K., Fon, E. A., and Durcan, T. M. (2019) One step Into the future: new iPSC tools to advance research in Parkinson's disease and neurological disorders, $J$ Parkinsons Dis 9, 265-281.

75. Centeno, E. G. Z., Cimarosti, H., and Bithell, A. (2018) 2D versus 3D human induced pluripotent stem cell-derived cultures for neurodegenerative disease modelling, Mol Neurodegener 13, 27. 
76. Chang, C. Y., Ting, H. C., Liu, C. A., Su, H. L., Chiou, T. W., Harn, H. J., and Lin, S. Z. (2018) Induced pluripotent stem cells: a powerful neurodegenerative disease modeling tool for mechanism study and drug discovery, Cell Transplant, 963689718775406.

77. Hay, M., Thomas, D. W., Craighead, J. L., Economides, C., and Rosenthal, J. (2014) Clinical development success rates for investigational drugs, Nat Biotechnol 32, 40-51.

78. Wu, Y. Y., Chiu, F. L., Yeh, C. S., and Kuo, H. C. (2019) Opportunities and challenges for the use of induced pluripotent stem cells in modelling neurodegenerative disease, Open Biol 9, 180177.

79. El-Brolosy, M. A., and Stainier, D. Y. R. (2017) Genetic compensation: a phenomenon in search of mechanisms, PLoS Genet 13, e1006780.

80. Weiss, W. A., Taylor, S. S., and Shokat, K. M. (2007) Recognizing and exploiting differences between RNAi and small-molecule inhibitors, Nat Chem Biol 3, 739-744.

81. Wells, C. I., Kapadia, N. R., Couñago, R. M., and Drewry, D. H. (2017) In depth analysis of kinase cross screening data to identify chemical starting points for inhibition of the Nek family of kinases, MedChemComm 9, 44-66.

82. Yu, N. N., Yu, J. T., Xiao, J. T., Zhang, H. W., Lu, R. C., Jiang, H., Xing, Z. H., and Tan, L. (2011) Tautubulin kinase-1 gene variants are associated with Alzheimer's disease in Han Chinese, Neurosci Lett 491, 83-86.

83. Lund, H., Cowburn, R. F., Gustafsson, E., Stromberg, K., Svensson, A., Dahllund, L., Malinowsky, D., and Sunnemark, D. (2013) Tau-tubulin kinase 1 expression, phosphorylation and co-localization with phospho-Ser422 tau in the Alzheimer's disease brain, Brain Pathol 23, 378-389.

84. Liachko, N. F., McMillan, P. J., Strovas, T. J., Loomis, E., Greenup, L., Murrell, J. R., Ghetti, B., Raskind, M. A., Montine, T. J., Bird, T. D., Leverenz, J. B., and Kraemer, B. C. (2014) The tau tubulin kinases TTBK1/2 promote accumulation of pathological TDP-43, PLoS Genet 10, e1004803.

85. Giacomini, C., Koo, C.-Y., Yankova, N., Tavares, I. A., Wray, S., Noble, W., Hanger, D. P., and Morris, J. D. H. (2018) A new TAO kinase inhibitor reduces tau phosphorylation at sites associated with neurodegeneration in human tauopathies, Acta Neuropathol Com 6, 37.

86. Hill-Burns, E. M., Wissemann, W. T., Hamza, T. H., Factor, S. A., Zabetian, C. P., and Payami, H. (2014) Identification of a novel Parkinson's disease locus via stratified genome-wide association study, BMC Genomics 15, 118-118.

87. Henderson-Smith, A., Chow, D., Meechoovet, B., Aziz, M., Jacobson, S. A., Shill, H. A., Sabbagh, M. N., Caviness, J. N., Adler, C. H., Driver-Dunckley, E. D., Beach, T. G., Yin, H., and Dunckley, T. (2013) SMG1 identified as a regulator of Parkinson's disease-associated alpha-synuclein through siRNA screening, PLoS One 8, e77711-e77711.

88. Ikeda, M., Takahashi, A., Kamatani, Y., Momozawa, Y., Saito, T., Kondo, K., Shimasaki, A., Kawase, K., Sakusabe, T., Iwayama, Y., Toyota, T., Wakuda, T., Kikuchi, M., Kanahara, N., Yamamori, H., Yasuda, Y., Watanabe, Y., Hoya, S., Aleksic, B., Kushima, I., Arai, H., Takaki, M., Hattori, K., Kunugi, H., Okahisa, Y., Ohnuma, T., Ozaki, N., Someya, T., Hashimoto, R., Yoshikawa, T., Kubo, M., and Iwata, N. (2018) Genome-wide association study detected novel susceptibility genes for schizophrenia and shared transpopulations/diseases genetic effect, Schizophr Bull. 